\section{Medical research and ethnic minorities}

\section{McDonald}

\section{Research-know thyself}

$\Lambda^{\mathrm{f}}$ ew years ago, I was a member of an international and interdisciplinary research team that was developing "a cross-cultural approach to health care ethics". Our work resulted in a volume that is widely used in advanced ethics education for health care professionals. At the conclusion of the research project, one of the team members decided to distil essential lessons in the form of short aphorisms. So she asked each member of the research team, "What single piece of wisdom would you draw from our threeyear project on cross-cultural health care ethics?"

My response was instantaneous. I said the beginning of wisdom for a health care professional working in cross cultural contexts was, "To know one's own culture!" Awareness of another person's culture is most acute when it is in contrast with one's own culture, for it is in such a comparative perspective that one becomes most aware of one's own cultural assumptions especially about the taken-for-granted or normal that is invisible to us in our everyday dealings with members of our culture. Often times it is these invisible assumptions about the normal that lead to cross cultural misunderstanding and ethically insensitive behaviour. Understanding our own culture can help inform and improve our interactions with people of other cultures.

These lessons of cultural self knowledge are, I believe, relevant to the situation of medical researchers from one culture conducting research involving people of another culture. Like other professionals, medical researchers bring to their work sets of largely unexamined assumptions and beliefs-in a nonpejorative sense, "prejudices" in the form of a set of pre-judgments about normal and abnormal human behaviour. Some of these pre-judgments arise from the researcher's ethnocultural location, while others come from the individual's occupational or professional background as a researcher and as a clinician. I will discuss these in turn to show how important cultural self awareness is in dealing with members of other cultures, in particular when a researcher from a dominant "majority" culture deals with research subjects from a disempowered minority culture.

In terms of ethnocultural self awareness, I would offer two current examples: one from cancer research and the second from my own experience in transplantation research. The first example from cancer research involves the challenges American researchers have had in recruiting African-Americans for participation in cancer trials. Fouad et al note that the cancer mortality rates for African-Americans are two and one half times as high as for white Americans and "treatment outcomes for some common malignancies ... are unfavourable [for African-Americans] compared with whites". ${ }^{2}$ At the same time, Fouad et al note that "minority accrual and retention in several large-scale National Cancer Institute cancer prevention trials has been lower than desired". To researchers from the white majority population, such under-participation in cancer prevention trials by African-Americans relative to risk exposure may appear to be anomalous compared with the majority population's more extensive participation.

In this situation, I believe that researchers would do well to reflect on why they think it "natural" and "normal" to want to participate in clinical trials. Such expectations about clinical trial participation are predicated on assumptions about potential participants normally being aware of and invited to participate in such trials, as well as having generally positive experiences of health care and the confidence to believe that medical research is likely be beneficial-if not for oneself, at least for others for whom one has concern. However, Fouad et al report that often African-Americans do not receive adequate information about clinical studies. Other researchers indicate that African-Americans may have negative beliefs and attitudes about medical research. Fouad and her colleagues identified a number of potential factors contributing to lower participation rates on the part of AfricanAmericans: less sense of ownership of programmes affecting health, less physician referral of patients, and the negative history of the infamous Tuskegee Syphilis Study. ${ }^{3}$ In a similar study of the attitude of African-Americans towards HIV research, Blanchard cites the Tuskegee study as well as noting a 1993 opinion poll showing "a significant portion of African-Americans, who believe that AIDS was a form of genocide". ${ }^{24}$ (However, in Fouad's study, a majority of participants indicated that the Tuskegee Syphilis Study was not a factor in decisions about participation in clinical trials.) My suggestion is that cultural self knowledge can help medical researchers avoid over-generalising and projecting their own cultural expectations regarding the value of medical research unto members of other cultural groups.

I draw my second example from a recent experience that I had as a member of a research team currently examining ethnocultural attitudes toward organ donation. Our research team gathered information through the use of individual interviews and focus groups. For two of the three groups we studied (Indo-Canadians and ChineseCanadians), both methods worked well. However, the third group (Native Canadians from the Coast Salish People) did not respond well to focus groups. We hypothesised that a number of factors could account for the problems we encountered in using a focus group methodology, including a history of negative interactions with researchers as well as adherence to traditional Native values, especially deference to elders and the sense that traditional knowledge may not be shared with outsiders. Among the majority populations in Canada, such attitudes would be uncommon. As researchers, we had simply assumed that Native Canadians would share the attitudes that we had as members of a dominant majority culture. When we reviewed the literature on focus groups, we also found that focus groups have been mainly used in mainstream communities. ${ }^{5}$ (Hall and $\mathrm{Na}$ gayama report a similar problem in regard to the lack of evidence for the use of empirically supported therapies with ethnic minorities.) So while our research group was quite attentive to potential differences in minority community attitudes toward organ donation, we had not been sufficiently sensitive to a minority group's response to one of our principal research methodologies. Greater awareness of our own culture's pre-judgments would have helped us understand these differences and deal with them in a more culturally sensitive manner. Hence, more attention to what we culturally took for granted as a "normal" mode of inquiry might well have led us to question whether the same favourable attitude toward focus groups appeared in all the minority populations that we were studying.

It is not just one's ethnocultural background that carries with it hidden value 
assumptions. Awareness of one's own occupational culture is also important in order to become aware of assumptions that clients, subjects, and members of the general population may not share. Physicians, nurses, scientists, and others involved in medical research should reflect on the often hidden assumptions and pre-judgments that underlie various types of health care research. Let me take as an example something that may at first seem obvious and uncontroversial, but which when more closely examined reveals important issues in research involving ethnic minorities. When medical researchers examine "at risk" populations, the identification of the population is in terms of medical factors that can be scientifically examined-for example, exposure to a common disease, diet and other health behaviours, shared genetic features, or exposure to particular environmental risks. If the researchers limit their concerns to these factors, they may miss what Belshe et al label as, "social risks" or "non-medical adverse outcomes" associated with participating in research ${ }^{6}$ cited in Blanchard. ${ }^{4}$ For example, the scientifically sound identification of Ashkenazi Jews as significantly at risk of Tay-Sachs disease has led to the description of Tay-Sachs as "the Jewish disease". This labelling is an example of a social risk. It gives rise to the poignant question raised in the title of a recent article by Wolpe, "If I am only my genes, what am I?" ${ }^{\prime 7}$ This is an issue that can arise in predictive testing generally. That is, once predictive testing is available for an at risk group, the members of the group perceive themselves negatively and are perceived by others negatively. Thus, as behavioural tests for Alzheimer's disease become more prevalent, essentially healthy research subjects redefine themselves as Alzheimer's patients in waiting-scrutinising every sign of memory loss for indications of the disease's inexorable process.

My point here is not to deny the value of medical research into socially stigmatised conditions or to argue against research on predictive testing even though such tests may well change how a group perceives itself and is perceived by others. Rather my concern is for researchers to become self aware of potential blind spots in a purely scientific perspective on study populations. This will help researchers to understand how adverse non-medical factors like social stigmatisation can affect research populations and encourage research to develop appropriate mitigating strategies. Such mitigating strategies may well include various forms of community involvement in the design, management, and presentation of research. It also should lead to greater education of research populations about the implications of participation in predictive testing or other studies.

Before concluding, I would offer a word of caution about attributing too much to cultural differences-whether these are ethnically or occupationally based cultural differences-while ignoring or underestimating other relevant factors such as wealth, social status, or education. That is, it is easy to overgeneralise and see all differences through the lens of culture. Here again self awareness can help the researcher. For researchers will readily recognise in their own case that they are as persons more than just members of a cultural or occupational grouping. That is, one is not just a researcher and a member of a cultural group; one is a person enmeshed as all humans are in a unique set of circumstances and relationships. It is frankly too easy to categorise and generalise about other humans and in effect pigeon hole them in ethnic and occupational terms. The anthropologist Patricia
Kaufert aptly describes this as "boxification". ${ }^{8}$ Boxification can lead the researcher to miss crucial variables like wealth and social status that often have a profound impact on health. It can also lead to a simplistic categorisation of members of particular groups, be they Asian immigrants or coal miners, as all being alike and ignoring medically and ethically relevant differences among them.

Postgrad Med J 2003;79:125-126

\section{Author's affiliation}

M McDonald, University of British Columbia, Vancouver, Canada

Correspondence to: Dr Michael McDonald 225-6356 Agricultural Road, Vancouver, BC, Canada V6T 122; mcdonald@ethics.ubc.ca

\section{REFERENCES}

1 Coward H, Ratanakul P, eds. A cross-cultural dialogue on health care ethics. Waterloo, ON: Wilfrid Laurier University Press, 1999.

2 Fouad MN, Partridge E, Wynn T, et al. Statewide Tuskegee alliance for clinical trials: a community coalition to enhance minority participation in medical research. Cancer 2001;91 (1 suppl):237-41

3 Pence GE. Classic cases in medical ethics. New York: McGraw Hill, 1990.

4 Blanchard L. Community assessment and perceptions: preparation for HIV vaccine efficacy trials. In: King NMP, Henderson GE, Stein J, eds. Beyond regulations: ethics in human subjects research. Chapel Hill, NC: University of North Carolina, 1998: 85-93.

5 Hall G, Nagayama C. Psychotherapy research with ethnic minorities: empirical, ethical and conceptual issues. Journal of Consulting and Clinical Psychology 2001;69:502-10

6 Belshe RB, Clements ML, Keefer MC, et al. Interpreting HIV seriodiagnostic test results in the early 1990s: social risks of HIV vaccine studies in uninfected volunteers. Ann Intern Med 1994:121:584-9.

7 Wolpe PR. If I Am only my genes, what am I? Genetic essentialism and a Jewish response. Kennedy Institute of Ethics Journal 1997:7:213-30.

8 Kaufert PA. The "boxification" of culture: the role of the social scientist. Santé Culture Health 1990;7:2-3. 